\title{
Microwave Drying of Apple Cubes - Effect of the Osmotic Pre-treatment and Comparison with Hot Air Drying
}

\author{
Fernanda Rosa Assis, Rui Manuel Santos Costa de Morais and Alcina Maria Miranda Bernardo de \\ Morais*
}

Universidade Católica Portuguesa, CBQF - Centro de Biotecnologia e Química Fina - Laboratório Associado, Escola Superior de Biotecnologia, Rua Arquiteto Lobão Vital, Apartado 2511, 4202-401 Porto, Portugal Email: abmorais@porto.ucp.pt

\begin{abstract}
The aim of the present work was to study the effects of the osmotic dehydration (OD) on the mass transfer kinetics of the microwave drying (MWD) and some quality parameters of apple cubes. The fit of several mathematical models was tested to describe the drying. A comparison between MWD and hot air drying (HAD) was performed. Apple cubes were osmotically treated with $60^{\circ}$ Brix sucrose or sorbitol solutions at $60^{\circ} \mathrm{C}$ and dried at a microwave power between 160 and 850 $\mathrm{W}$. Overall, the increase of the microwave power from 160 to $500 \mathrm{~W}$ resulted in an increase of the water loss rate, shown by the A parameter of modified Page's model, of 123 and $155 \%$ for samples osmotically dehydrated with sucrose and sorbitol solutions, respectively. The OD tends to increase the drying rate, but the osmotic agent used did not have any effect. The modified Page's model described well the drying kinetics and MWD was faster than HAD. The water activity of the osmotically dehydrated product was reduced to below 0.4 after MWD at $500 \mathrm{~W}$. The MWD of control samples resulted in a loss of $39 \%$ and $28 \%$ of the total phenolic content and the antioxidant activity, respectively. For osmotically dehydrated samples, a loss of around $75 \%$ was observed for both these quality parameters after the osmotic treatment.
\end{abstract}

Keywords: Apple cubes, osmotic treatment, microwave drying, hot air drying, mass transfer, mathematical models.

\begin{tabular}{|c|c|c|c|}
\hline \multicolumn{4}{|c|}{ Nomenclature } \\
\hline$a$ & half of the side of the cube $(\mathrm{m})$ & $k$ & Newton's parameter \\
\hline$a_{w}$ & water activity & $m$ & mass of sample $(\mathrm{g})$ \\
\hline \multirow[t]{2}{*}{$A, B$} & Page's and Modified Page's models & $M$ & moisture content (kg water.kg dry matter ${ }^{-1}$ ) \\
\hline & parameters & $M_{m}$ & monolayer moisture content (kg water.kg dry \\
\hline \multirow[t]{2}{*}{$a, k$} & $\begin{array}{l}\text { Henderson and Pabis' and Two- } \\
\text { term }\end{array}$ & & matter $\left.^{-1}\right)$ \\
\hline & exponential models parameters & $M_{0}$ & initial moisture content (kg water.kg dry matter ${ }^{-1}$ ) \\
\hline$a, k_{1}, b, k_{2}$ & Two-term model parameters & $M_{\infty}$ & moisture content at equilibrium (kg water.kg dry \\
\hline$a, k, c$ & Logarithimic model parameters & & matter $\left.^{-1}\right)$ \\
\hline$a, b$ & $\begin{array}{l}\text { Wang and Singh's model } \\
\text { parameters }\end{array}$ & $M R$ & moisture ratio \\
\hline$a, k, n, b$ & Midilli et al.'s model parameters & MWD & microwave drying \\
\hline$a, k, b, B$ & Weibull's model parameters & OD & osmotic dehydration \\
\hline$c, k$ & GAB's model constants & $p$ & Arrhenius's parameter \\
\hline$D_{e}$ & effective diffusivity $\left(\mathrm{m}^{2} \cdot \mathrm{s}^{-1}\right)$ & $p_{0}$ & Arrhenius's parameter at the reference temperature \\
\hline $\mathrm{DM}$ & dry matter & $P$ & microwave power $(\mathrm{W})$ \\
\hline$E_{a}$ & activation energy $\left(\mathrm{W} \cdot \mathrm{g}^{-1}\right)$ & SHW & standard half width \\
\hline HAD & hot air drying & $t$ & time $(\mathrm{s})$ \\
\hline
\end{tabular}




\section{Introduction}

Dehydration aims to increase the shelf life of the food when compared with the fresh product due to the reduction of the water content, and, consequently, to the decrease of the water activity $\left(\mathrm{a}_{\mathrm{w}}\right)$ [1]. The OD is often used as pre-treatment with the aim to reduce the time and also the losses in volatile compounds and the risk of chemical and physical changes of the subsequent drying process [2].

In the most conventional types of drying, such as HAD, the product is normally processed during a long time. This can lead to undesirable flavour, colour, and nutrient content, besides presenting a high energy consumption. With the aim to reduce the nutritional losses, as well as to achieve a fast and effective process, the MWD may be used [3]. The microwaves interact directly with the polar water molecules to generate heat, which, consequently, causes a rapid evaporation of water $[4,5]$.

The mass transfer kinetics of the MWD has been studied by many researchers, and different mathematical models have been used to describe the kinetics of this process. Çelen and Kahveci [4] studied the MWD of tomato slices and concluded that the drying time and the energy consumption decreased with the increase of the microwave power $(90-600 \mathrm{~W})$. Doymaz et al. [5] also found that the increase of the microwave power decreased the drying time of green bean slices. They used several models - Lewis', Henderson and Pabis', Logarithmic, Verma et al.'s, Page's, Midilli et al.'s, Parabolic, Wang and Singh's, Weibull's — to fit the drying data and they concluded that the Midilli et al.'s model presented the best fit. This model was also able to describe well the MWD kinetics of white mulberry [6], mango ginger [7], with microwave powers between 90 and $900 \mathrm{~W}$.

Fang et al. [8] concluded that the MWD of Chinese jujube was better than HAD, resulting in a product with higher vitamin $\mathrm{C}$ content and less shrinkage. Horuz and Maskan [9] also compared the same methods of drying pomegranate arils and found that the drying rate was higher in MWD.

The objectives of this work were: i) to evaluate the effect of the osmotic pre-treatment and the microwave power on the water loss kinetics of the MWD and some quality parameters, such as the water activity, the colour, the total phenolic content and the antioxidant activity of apple cubes (variety Royal Gala); ii) to test the adequacy of the fitness of several mathematical models in describing the moisture content of the product during the drying; iii) to carry out the comparison between the MWD and the HAD of osmotically pre-treated apple cubes.

\section{Materials and Methods}

\subsection{Samples}

Apples (Malus spp., variety Royal Gala) were graciously supplied by Campotec, Portugal, and stored at $4^{\circ} \mathrm{C}$. The fruits were washed and sanitized with aqueous solution with $7500 \mathrm{ppm}$ active chlorine for 5 min. Then, the samples were cut in cubes $(12 \times 12 \times 12 \mathrm{~mm})$ with a vegetable cutter (Secret de Gourmet, JJA, Le Blanc Mesnil, France) and immersed in a solution with $0.9 \%$ sodium chloride for 3 min to prevent enzymatic browning. The samples were blotted gently with tissue paper in order to remove the excess of sodium chloride solution from the surface. The soluble solids content of the apples was $17.81 \pm$ $0.97^{\circ}$ Brix (hand refractometer, Atago, U.S.A., Inc., WA, USA).

\subsection{Osmotic Dehydration}

The apple samples were immersed in a $60^{\circ}$ Brix osmotic solution of sucrose or sorbitol for $8 \mathrm{~h}$ at $60^{\circ} \mathrm{C}$ and atmospheric pressure. The mass ratio of sample to solution used was 1:4 [10].

\subsection{Microwave Drying}

The MWD experiments were performed in a domestic microwave oven (MT-243, Whirlpool, USA).

The drying experiments were carried out at six different power levels — 160, 350, 500, 650, 750 and $850 \mathrm{~W}$. Fifteen cubes were used in each drying experiment. The cubes were placed in a plastic container and this was put at the edge of the rotating glass plate. The samples were taken every 5 min until 20 to 
40 min, depending on the power output and the sample appearance. Each drying experiment was carried out twice.

\subsection{Moisture Content Determination}

The moisture content was determined in an oven (FP115, Binder, Tuttlingen, Germany) at $105^{\circ} \mathrm{C}$ until constant weight [11]. The determinations were performed in triplicate.

\subsection{Water Activity Determination}

The $\mathrm{a}_{\mathrm{w}}$ of the samples was determined during the process. It was determined with a hygrometer (Aqualab Series 3, Decagon Devices Inc., Pullmam, Washington, USA) at $22{ }^{\circ} \mathrm{C}$. Each determination was performed in duplicate.

\subsection{Quality Evaluation}

The colour, the total phenolic content and the antioxidant activity of the product dried at the condition which produced the best MWD rate, were evaluated.

\subsubsection{Colour}

The colour of the samples was measured using Minolta CR-300 colorimeter (Konica-Minolta, Osaka, Japan) in the CIE $L^{*} a^{*} b^{*}$ mode CIELAB colour space [12]. The colour was determined by five measures on three replicates for each sample. The saturation index or chroma $(\mathrm{C})$, the total colour difference $(\Delta \mathrm{E})$ and the browning index were calculated by the following equations:

$$
\Delta \mathrm{E}=\sqrt{\left(L_{0}^{*}-L^{*}\right)^{2}+\left(a_{0}^{*}-a^{*}\right)^{2}+\left(b_{0}^{*}-b^{*}\right)^{2}}
$$

where the index " 0 " indicates the sample before MWD.

$$
\begin{aligned}
& \text { Browning index }=\frac{100 \cdot(x-0.31)}{0.17} \\
& \text { with } x=\frac{a^{*}+1.75 L^{*}}{5.645 L^{*}+a^{*}-3.012 b^{*}}
\end{aligned}
$$

\subsubsection{Total Phenolic Content}

The extracts for the determination of the total phenolic content and the antioxidant activity were prepared by homogenising approximately $1 \mathrm{~g}$ of dried apple cubes with $10 \mathrm{~mL}$ of methanol (Sigma Aldrich) using an ultra-turrax (T25, IKA, Germany). After that, the homogenized solutions were centrifuged at $5000 \mathrm{rpm}$ and $4^{\circ} \mathrm{C}$ for $15 \mathrm{~min}$ and filtrated (adapted from [13]).

The total phenolic content was determined in the methanolic extracts by the Folin-Ciocalteu method [14]. The reaction was performed by adding $0.5 \mathrm{~mL}$ apple extract, $0.5 \mathrm{~mL}$ Folin-Ciocalteu reagent, $1 \mathrm{~mL}$ sodium carbonate 75 (g. $\mathrm{L}^{-1}$ ) (Sigma-Aldrich) and $1.4 \mathrm{~mL}$ of deionized water. The total phenolic content was determined after $1 \mathrm{~h}$ at $750 \mathrm{~nm}$ in a UV-visible spectrophotometer (1240, Shimadzu, Japan). Quantification was done with respect to the standard curve of the gallic acid. The determinations were carried out in triplicate.

\subsubsection{Antioxidant Activity}

The ABTS method was used to determine the antioxidant activity [15]. After addition of $1 \mathrm{~mL}$ of $\mathrm{ABTS}^{+}$solution (absorbance $=0.700 \pm 0.02$ ) to $0.2 \mathrm{~mL}$ of extract, the analysis was performed after 6 min at $734 \mathrm{~nm}$ and expressed as $\mathrm{mg}$ ascorbic acid.g $\mathrm{DM}^{-1}$. The determinations were performed in triplicate.

\subsection{Mathematical Models}

The moisture ratio $(M R)$ of the samples was used to describe the experimental data during the drying process: 


$$
M R=\frac{M-M_{\infty}}{M_{0}-M_{\infty}}
$$

$M_{0}$ is the initial moisture content, $M$ is the moisture content at time $t$, and $M_{\infty}$ is the moisture content at equilibrium, all in dry basis $\left(\mathrm{kg}_{\text {water }} \cdot \mathrm{kg}_{\text {dry matter }}{ }^{-1}\right)$. All $M_{\infty}$-values were predicted by the models.

Eleven mathematical models were used to carry out the fit of the experimental data during the MWD of the osmotically dehydrated apple cubes. The equations of the models are described below:

$$
\begin{aligned}
& \text { Newton } \\
& \text { Page } \\
& M R=\exp (-k . t) \\
& M R=\exp \left(-A \cdot t^{B}\right)
\end{aligned}
$$

Modified Page

Henderson and Pabis

$$
M R=\exp \left(-(A . t)^{B}\right)
$$

$$
M R=a \cdot \exp \left(-k_{1} \cdot t\right)
$$

Two-term

$$
M R=a \cdot \exp \left(-k_{1} \cdot t\right)+b \cdot \exp \left(-k_{2} \cdot t\right)
$$

Two-term exponential

$$
M R=a \cdot \exp (-k . t)+(1-a) \cdot \exp (-k . a . t)
$$

Logarithmic

$$
M R=a \cdot \exp (-k \cdot t)+c
$$

Wang and Singh

$$
M R=1+a \cdot t+b \cdot t^{2}
$$

Midilli et al.

$$
M R=a \cdot \exp \left(-k \cdot t^{n}\right)+b \cdot t
$$

Weibull

$$
M R=a-b \cdot \exp \left(-\left(k \cdot t^{B}\right)\right)
$$

Crank

$$
M R=\left[\sum_{n=0}^{\infty} \frac{8}{(2 n+1)^{2} \cdot \pi^{2}} \exp \left(-\frac{(2 n+1)^{2} \cdot \pi^{2} \cdot \text { De.t }}{4 a^{2}}\right)\right]^{3}
$$

The Guggenheim-Anderson-de Boer (GAB)'s model was used to predict the relation between the equilibrium moisture content and the $\mathrm{a}_{\mathrm{w}}$ of the dried apple cubes [16]. The GAB's model is expressed as:

$$
\frac{M_{\infty}}{M_{m}}=\frac{c \cdot k \cdot a_{w}}{\left(1-k \cdot a_{w}\right) \cdot\left(1-k \cdot a_{w}+c \cdot k \cdot a_{w}\right)}
$$

$\mathrm{c}$ and $\mathrm{k}$ are constants and $\mathrm{Mm}$ is described as the monolayer moisture content on dry basis (kgwater.kgdry matter-1).

\subsection{The Arrhenius' Behaviour}

The linearized Arrhenius equation was used to study the dependence of the parameters $A$ and $B$ of the modified Page's model on the microwave power [17]:

$$
\ln p=\ln p_{0}-\frac{m \cdot E a}{P}
$$

$p$ is the parameter $(A$ or $B) ; p_{0}$ is the Arrhenius factor; $m$ is the mass of sample; $E_{a}$ is the activation energy $\left(\mathrm{W} \cdot \mathrm{g}^{-1}\right) ; P$ is the microwave power $(\mathrm{W})$. 


\subsection{Statistical Analysis}

The statistical analysis was performed using Microsoft Excel 2000 (Microsoft Corporation, USA) (mean and standard deviation calculations) and IBM SPSS® Statistics 20.0 for Windows ${ }^{\circledR}$ (2012, SPSS Inc., Chicago, USA). The models presented above were used to fit the experimental data obtained at the different conditions tested. The model parameters were estimated by non-linear regression procedures, and the margin of error of the estimates was calculated at 95\% (the margin of error is the half width of the confidence interval at 95\%). The regressions were also assessed by ANOVA approaches and the significance level assumed was $5 \%$.

The adequacy of the models fit was evaluated by the determination coefficient $\left(R^{2}\right)$ and by the residual analysis. Normality of the residuals was evaluated by Kolmogorov-Smirnov test.

\section{$3 \quad$ Results and Discussion}

The MWD experiments were first carried out with fresh samples for all power levels. Then, the MWD experiments were performed with the samples osmotically treated with the sucrose solution at 160, 350, 500, 750 and $850 \mathrm{~W}$. In these experiments, no significant difference was observed between 500 and 750 W. Thus, the MWD experiments with the samples osmotically treated with sorbitol were first carried out at extreme power levels, 160 and $850 \mathrm{~W}$, and, then, $500 \mathrm{~W}$.

\subsection{Mathematical Modelling}

The Page's, modified Page's, Midilli et al.'s, logarithmic, two-term exponential and Weibull's models presented high values of the determination coefficient $\left(\mathrm{R}^{2}>0.9\right)$ of the non-linear regression of the experimental data of the MWD of apple cubes for all conditions. The residual analysis showed that the residuals were normally distributed at the significance level of $5 \%$; the visual analysis of the scatterplot of the residuals vs. the predicted values allowed to observe that the residuals were distributed randomly around zero with no systematic patterns, satisfying the assumption of homoscedasticity and zero mean errors. The other models did not describe well the experimental data because they did not follow one or more of the assumptions described above.

Weibull's, Two-term exponential and logarithmic models presented high values of margin of error, making the parameters not significantly different among the different conditions used. Therefore, the best fit was selected based on the precision in parameter estimation, calculated though the Standard Half Width (SHW = margin of error/ parameter value) at 95\% of confidence. The average of the SHW was $40 \%, 18 \%$ and $574 \%$ for the Page's, modified Page's and Midilli et al.'s modells, respectively. Thus, the modified Page's model described better the kinetics of MWD of apples cubes, with the highest precision of parameter estimates (i.e., lowest SHW) for all conditions used (Figures 1-3, Table 1).

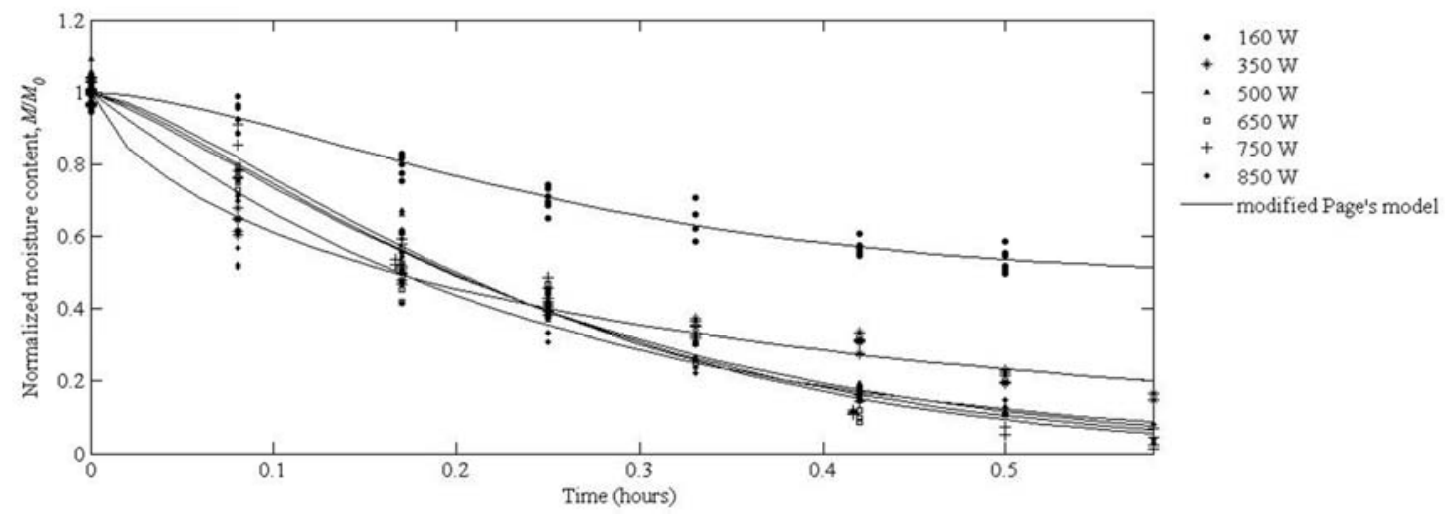

Figure 1. Experimental data and fit of modified Page's model of the normalized moisture content $\left(M / M_{0}\right)$ during the microwave drying of fresh apple cubes 


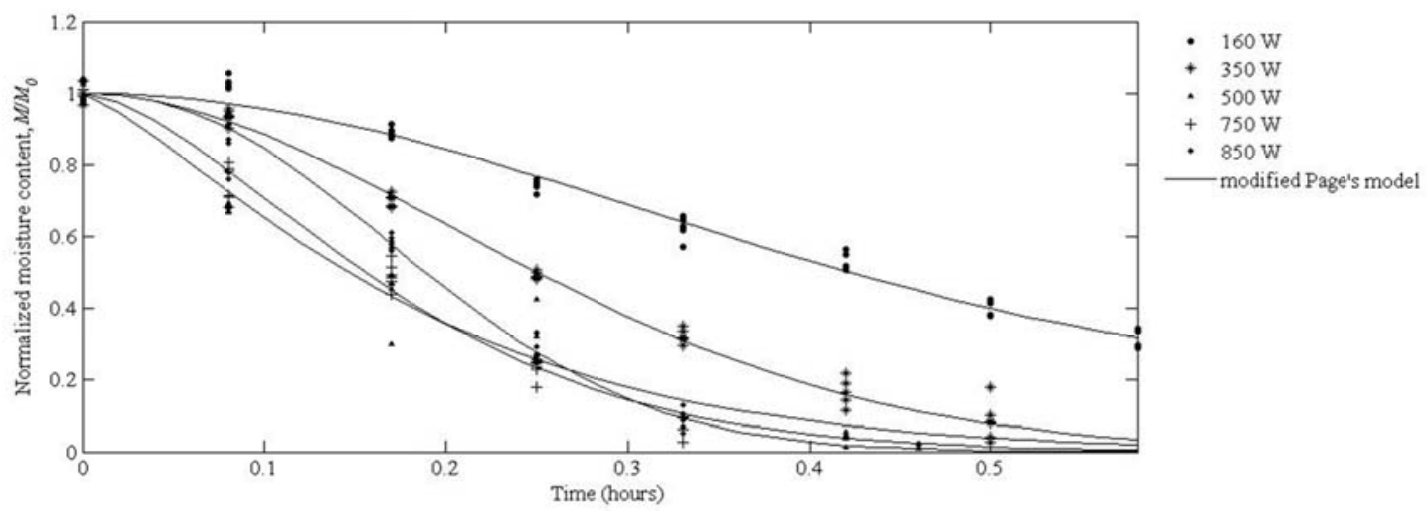

Figure 2. Experimental data and fit of modified Page's model of the normalized moisture content (M/M0) during the microwave drying of apple cubes osmotically pre-treated with a $60^{\circ}$ Brix sucrose solution

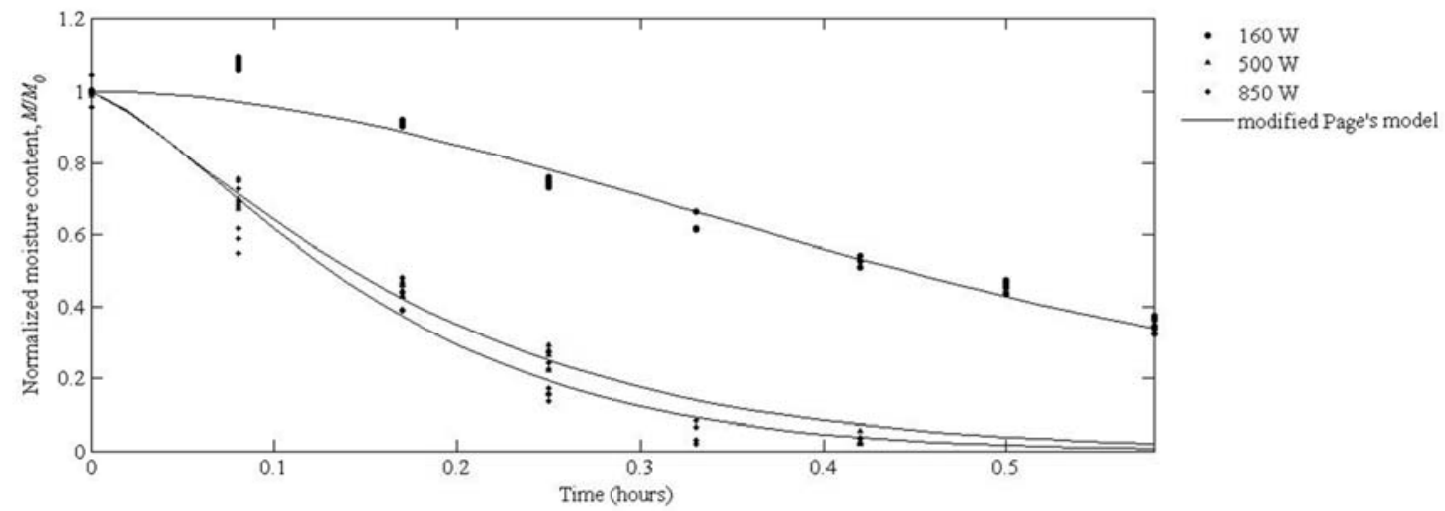

Figure 3. Experimental data and fit of modified Page's model of the normalized moisture content (M/M0) during the microwave drying of apple cubes osmotically pre-treated with a $60^{\circ}$ Brix sorbitol solution

Table 1. Parameters of the fit of modified Page's model of experimental data from microwave drying of apple cubes

\begin{tabular}{c|c|c|c|c}
\hline \multirow{2}{*}{ Osmotic agent of OD } & \multirow{2}{*}{ Power level } & \multicolumn{3}{|c}{ modified Page' s model } \\
\cline { 3 - 5 } & & $\mathrm{A}\left(\mathrm{kg}_{\text {water }} \cdot \mathbf{k g}_{\text {dry }}\right.$ matter $\left.^{-1} \cdot \mathrm{h}^{-1}\right) \pm$ margin of error & $\mathrm{B} \pm$ margin of error & $\mathrm{R}^{2}$ \\
\hline- & 160 & $3.587 \pm 0.657$ & $1.496 \pm 0.321$ & 0.968 \\
\hline sucrose & 160 & $2.287 \pm 0.159$ & $1.979 \pm 0.192$ & 0.988 \\
\hline sorbitol & 160 & $2.037 \pm 0.312$ & $1.872 \pm 0.295$ & 0.975 \\
\hline- & 350 & $3.497 \pm 2.274$ & $0.672 \pm 0.151$ & 0.990 \\
\hline sucrose & 350 & $3.290 \pm 0.234$ & $1.882 \pm 0.170$ & 0.994 \\
\hline- & 500 & $3.769 \pm 0.711$ & $1.208 \pm 0.209$ & 0.984 \\
\hline sucrose & 500 & $5.101 \pm 0.759$ & $1.262 \pm 0.213$ & 0.958 \\
\hline sorbitol & 500 & $5.200 \pm 0.718$ & $1.240 \pm 0.179$ & 0.991 \\
\hline- & 650 & $3.806 \pm 0.698$ & $1.265 \pm 0.199$ & 0.984 \\
\hline- & 750 & $3.814 \pm 0.641$ & $1.343 \pm 0.232$ & 0.983 \\
\hline sucrose & 750 & $5.076 \pm 0.226$ & $1.564 \pm 0.176$ & 0.979 \\
\hline- & 850 & $4.158 \pm 1.173$ & $1.021 \pm 0.225$ & 0.983 \\
\hline sucrose & 850 & $4.477 \pm 0.376$ & $2.209 \pm 0.299$ & 0.993 \\
\hline sorbitol & 850 & $5.806 \pm 1.818$ & $1.339 \pm 0.396$ & 0.962 \\
\hline & & & & \\
\hline
\end{tabular}




\subsection{Mass Transfer Kinetics}

From previous experiments [10], the osmotically treated samples presented a water loss of $63 \%$ for both solutions used and a solid gain of $11 \%$ and $16 \%$ for sucrose and sorbitol, respectively, after $8 \mathrm{~h}$ of the OD process.

With the aim to minimize the variability of the experimental data at the beginning of the MWD, the moisture content, $M$, was normalized $(M / M 0)$.

The moisture ratio of the apple cubes, fresh or osmotically pre-treated, dried by MWD decreased with time and the process lasted less time when the microwave power was increased. These findings are in agreement with Çelen and Kahveci [4], Doymaz et al. [5] and Horuz and Maskan [9] .

The comparison of the process conditions was made based on the fit of the modified Page's model. The parameter $A$ was used to compare the variables used, the pre-treatment and the power levels. The $A$-values varied between 2.037 and 5.806. In relation to the power of MWD used it was possible to observe that this variable did not affect the drying rate of the fresh apples. For samples osmotically pretreated with the sucrose and sorbitol solution, the drying rate increased with the increase of power level until $500 \mathrm{~W}$, but power levels higher than $500 \mathrm{~W}$ did not produce significant differences. The increase of the power level from $160 \mathrm{~W}$ to $500 \mathrm{~W}$ resulted in an increase in the A-value of $123 \%$, for the pretreatment with sucrose solution. For the pre-treatment with the sorbitol solution, the drying rate increased by $155 \%$ when the power level increased from $160 \mathrm{~W}$ to $500 \mathrm{~W}$. Doymaz et al. [5] found that the drying rate of green bean slices increased by $275 \%$ when the microwave power output increased from 180 to $800 \mathrm{~W}$.

A-value did not follow a clear pattern for all the initial matrices used (fresh, osmotically dehydrated with sucrose or sorbitol solutions), but tends to be higher for pre-treated samples. Therdthai and Visalrakkij [18] used the Page's model to describe the moisture ratio during the microwave vacuum drying of mangosteen and the parameter $A$ presented the same tendency for all fruit matrices. Zhao et al. [19] found lower MWD rates in osmotically treated chili, compared with the fresh samples. In relation to the osmotic agent used, it did not seem to affect the water loss rate during the MWD.

The Arrhenius's behaviour was not observed for the $A$ and $B$ parameters of modified Page's model, meaning that these parameters were not correlated (low $\mathrm{R}^{2}$ ) with the microwave power used in the experiments of the present work. Doymaz et al. [5] and Murthy and Manohar [7] found that the effective diffusivity correlated well with the microwave power and presented values for $E a$ of around $20 \mathrm{~kW} \cdot \mathrm{kg}^{-1}$ during the MWD of green bean and mango ginger, respectively. These findings may be explained by the fact that Crank's is a phenomenological model (Assis et al. [10]) and would allow to obtain a correlation with physical meaning, while modified Page's is just an empirical one (as stated above, Crank's model could not produce a good fit of the experimental data).

Compared with the HAD previously studied [20], the drying rate was significantly higher in MWD. This comparison is based on the results of the fit if modified Page's model, which was able to describe the mass transfer kinetics of both drying processes in the conditions used. Considering the best condition of each - MWD-500W and $\mathrm{HAD}-80^{\circ} \mathrm{C}$ - the $A$ parameter increased from 1.612 (HAD) to 5.101 (MWD), i.e. a 3.2-fold increase, and from 1.834 (HAD) to 5.200 (MWD), i.e. a 2.8-fold increase, for osmotically treated samples with sucrose and sorbitol, respectively, and from 1.405 to 3.769 for control samples, i.e. around a 2.7-fold increase for control samples. Horuz and Maskan [9] found a 16.8-fold increase of the $A$-value (Page's model) for MWD at MWD-490W in relation to HAD- $70{ }^{\circ} \mathrm{C}$ of drying pomegranate arils.

\subsection{Water Activity (aw)}

The $\mathrm{a}_{\mathrm{w}}$ of the fresh samples was $0.986 \pm 0.003$ and of the osmotically treated samples with sucrose and sorbitol was $0.942 \pm 0.006$ and $0.899 \pm 0.006$, respectively. The $\mathrm{a}_{\mathrm{w}}$ of all samples decreased with the decrease of the water content. The lowest $\mathrm{a}_{\mathrm{w}}$-value was achieved in the dried samples osmotically treated with sorbitol (Table 2). 
Table 2. Water activity of osmotically treated apple cubes dehydrated by microwave

\begin{tabular}{c|c|c|c}
\hline Osmotic agent of OD & Power level & $\mathrm{t}(\mathrm{min})$ & $\mathrm{a}_{\mathrm{w}}$ \\
\hline- & 160 & 35 & $0.926 \pm 0.004$ \\
\hline sucrose & 160 & 45 & $0.580 \pm 0.033$ \\
\hline sorbitol & 160 & 45 & $0.463 \pm 0.020$ \\
\hline- & 350 & 35 & $0.805 \pm 0.004$ \\
\hline sucrose & 350 & 30 & $0.363 \pm 0.029$ \\
\hline- & 500 & 35 & $0.451 \pm 0.034$ \\
\hline sucrose & 500 & 27.5 & $0.340 \pm 0.001$ \\
\hline sorbitol & 500 & 25 & $0.247 \pm 0.020$ \\
\hline- & 650 & 35 & $0.414 \pm 0.009$ \\
\hline- & 750 & 35 & $0.292 \pm 0.102$ \\
\hline sucrose & 750 & 20 & $0.342 \pm 0.003$ \\
\hline- & 850 & 35 & $0.411 \pm 0.005$ \\
\hline sucrose & 850 & 20 & $0.472 \pm 0.020$ \\
\hline sorbitol & 850 & 20 & $0.264 \pm 0.011$ \\
\hline & & &
\end{tabular}

The final $\mathrm{a}_{\mathrm{w}}$ of fresh samples dehydrated at $500 \mathrm{~W}$ was around 0.4 . The osmotic pre-treatment reduced the final $\mathrm{a}_{\mathrm{w}}$ by 25 and $45 \%$, using sucrose and sorbitol, respectively, as osmotic agent.

The GAB's model expressed well the desorption isotherms of osmotically treated apple cubes dehydrated by MWD, but no significant differences were observed among the microwave powers and the pre-treatments did not show a clear pattern (data not shown). The values of $M m$ ranged from 0.031 to 0.290 and tended to be higher in osmotically treated samples. This may be due in part to the osmotic treatment, which may have caused a greater number of water molecules to be retained in the monolayer [21].

At the end of the drying process, the HAD produced samples with $\mathrm{a}_{\mathrm{w}}$ around 0.3 , near to the values found for MWD, but at different times. The MWD at $500 \mathrm{~W}$ reduced the drying time by $80 \%$ in relation to the HAD at $80{ }^{\circ} \mathrm{C}[20]$.

\subsection{Quality of the Final Product}

$\mathrm{L}^{*}$ and $\mathrm{a}^{*}$ values (Table 3$)$ were significantly $(\mathrm{p}<0.05)$ affected by the process. The $\mathrm{L}^{*}$ values decreased with the osmotic treatment and the MWD at $500 \mathrm{~W}$ and the highest $\mathrm{L}^{*}$ was found for the control. This can be explained by Maillard and non-enzymatic browning reactions that can occur during the drying process [22]. This reduction was also observed by Doymaz et al. [5] after the MWD of green bean slices. The redness/greenness component $\mathrm{a}^{*}$ increased after the processing. Chauhan et al. [23] observed the same after the OD of apple slices using different types of osmotic agent. The parameter $\mathrm{b}^{*}$ (values not shown) was not affected by neither the OD nor the MWD. The C-values were not significantly different among the samples. Izli et al. [24] observed that the goldenberry after the MWD presented lower $\mathrm{C}$ and $\mathrm{a}^{*}$ values compared with the fresh samples. The colour difference $(\Delta \mathrm{E})$ for all treatments did not show significant differences. So, it can be concluded that the MWD resulted in the same colour change independently if the pre-treatment was used. However and as expected, the lower browning index was found for the fresh samples. The dried samples previously osmotically treated presented the highest values of this parameter (Table 3).

The total phenolic content (TPC) of the fresh apple was $4.21 \pm 0.09 \mathrm{mg}$ gallic acid.g $\mathrm{DM}^{-1}$, i.e. $62.5 \pm 1.6 \mathrm{mg}$ gallic acid.100 $\mathrm{g}_{\text {fresh }}$ weight $^{-1}$ (Table 3 ). This value was lower than those obtained by Imeh and Khokhar [25] and Valavanidis et al. [26] for the same fruit, which were $300-500$ and $80-196$ $\mathrm{mg}$ gallic acid.100 $\mathrm{g}$ fresh weight ${ }^{-1}$, respectively. This difference can be explained by the fact that they used the whole fruit, while in this work the peel was removed, and TPC is higher in the peel [26].

The MWD had an effect on total phenolic content of the control samples. This process significantly decreased this content from 4.21 to $2.58 \mathrm{mg}$ gallic acid.g $\mathrm{DM}^{-1}$, meaning a $39 \%$ loss. Chong et al. [13] found a reduction of these compounds of about 9 to $63 \%$ when fruits were dried by different methods, in 
relation to the fresh sample. The same was not observed for the osmotically dehydrated samples, which did not present significant differences before and after the MWD. Therefore, the decrease in total phenolic content was mainly due the OD and was $75 \%$ to $77 \%$. This decrease was also observed by Novaković et al. [27] in a study OD of raspberries. According to them, the phenolic can migrate into the osmotic solution during the OD, inducing a loss of these compounds.

The results on the antioxidant activity (Table 3) showed a similar trend as the total phenolic content. The antioxidant activity of the fresh samples was $4.69 \pm 0.23 \mathrm{mg}$ ascorbic acid. $\mathrm{g} \mathrm{DM}^{-1}$ and the MWD reduced this value by $30 \%$ in the control samples. In the osmotically dehydrated samples, the reduction of this parameter occurred during the OD, i.e., the values being maintained after the MWD.

The type of solute used in the osmotic solution did not affect the total phenolic content or the antioxidant activity. The TPC of the apple cubes was related to the antioxidant activity. The correlation coefficient $\left(\mathrm{R}^{2}\right)$ between these parameters was 0.984, suggesting that the phenolic is mainly responsible for the antioxidant activity [13].

Table 3. Quality parameters of osmotically treated apples cubes dehydrated by microwave at $500 \mathrm{~W}$

\begin{tabular}{l|c|c|c|c|c|c|c}
\hline Treatment & $\mathrm{L}^{*}$ & $\mathrm{a}^{*}$ & $\mathrm{C}$ & $\Delta \mathrm{E}$ & $\begin{array}{c}\text { Browning } \\
\text { index }\end{array}$ & $\begin{array}{c}\text { Total phenolic } \\
\left(\begin{array}{c}\text { mg of gallic acid. } \\
\left.\text { g DM }^{-1}\right)\end{array}\right.\end{array}$ & $\begin{array}{c}\text { Antioxidant activity } \\
(\mathrm{mg} \text { ascorbic acid. } \\
\left.\mathrm{DM}^{-1}\right)\end{array}$ \\
\hline control & $69.39 \pm 1.79^{\mathrm{a}}$ & $-4.78 \pm 0.54^{\mathrm{c}}$ & $29.30 \pm 0.69^{\mathrm{a}}$ & 0 & $46.77 \pm 1.25^{\mathrm{d}}$ & $4.21 \pm 0.09^{\mathrm{a}}$ & $4.69 \pm 0.23^{\mathrm{a}}$ \\
\hline MWD & $61.96 \pm 11.07^{\mathrm{b}}$ & $4.34 \pm 3.82^{\mathrm{a}}$ & $30.30 \pm 0.98^{\mathrm{a}}$ & $7.31 \pm 0.83^{\mathrm{a}}$ & $55.01 \pm 4.02^{\mathrm{b}, \mathrm{c}}$ & $2.58 \pm 0.09^{\mathrm{b}}$ & $3.39 \pm 0.09^{\mathrm{b}}$ \\
\hline $\begin{array}{l}\text { OD sucrose } \\
+ \text { M sucrose }\end{array}$ & $61.83 \pm 2.96^{\mathrm{b}}$ & $-1.90 \pm 1.30^{\mathrm{b}}$ & $27.92 \pm 1.46^{\mathrm{a}}$ & $7.61 \pm 2.45^{\mathrm{a}}$ & $53.18 \pm 5.43^{\mathrm{c}}$ & $1.06 \pm 0.01^{\mathrm{c}}$ & $1.21 \pm 0.08^{\mathrm{c}}$ \\
\hline \begin{tabular}{l} 
OD sorbitol \\
\hline $\begin{array}{l}\text { OD sorbitol } \\
+ \text { MWD }\end{array}$
\end{tabular} & $55.28 \pm 2.24^{\mathrm{c}}$ & $2.79 \pm 0.79^{\mathrm{a}}$ & $29.30 \pm 2.32^{\mathrm{a}}$ & $8.41 \pm 1.87^{\mathrm{a}}$ & $74.63 \pm 5.85^{\mathrm{a}}$ & $1.05 \pm 0.04^{\mathrm{c}}$ & $1.18 \pm 0.06^{\mathrm{c}}$ \\
\hline
\end{tabular}

\section{Conclusion}

The osmotic pre-treatment with a $60^{\circ}$ Brix sorbitol solution prior to MWD represents an advantage in comparison with HAD due to the increase of the drying rate, which is an advantage for energy savings, and to the reduction of the final $\mathrm{a}_{\mathrm{w}}$ at the end of process. Besides this, sorbitol presents benefits because it is a prebiotic with proven health properties. However, this pre-treatment causes the reduction of some important quality parameters, such as the phenolic content and the antioxidant activity.

The modified Page's model was selected to describe the kinetics of MWD of apples cubes, for presenting the highest precision of parameter estimates among some other models that could fit the moisture ratio well during the MWD process.

Acknowledgement. This work was supported by National Funds from FCT - Fundação para a Ciência e Tecnologia through project UID/Multi/50016/2013. The first author acknowledges the financial support of CAPES (1528/13-0). The authors also acknowledge Campotec for graciously supplying the apples for this study.

\section{References}

1.M. Zhang, J. Tang, A. S. Mujumdar and S. Wang, "Trends in microwave-related drying of fruits and vegetables," Trends in Food Science and Technology, vol. 17, pp. 524-534, 2006.

2. J. R Arballo, L. A. Campañone and R. H. Mascheroni, "Modeling of microwave drying of fruits. Part II: Effect of osmotic pretreatment on the microwave dehydration process," Drying Technology, vol. 30, pp. 404-415, 2012.

3. J. Bondaruk, M. Markowski and W. Błaszczak, "Effect of drying conditions on the quality of vacuum-microwave dried potato cubes," Journal of Food Engineering, vol. 81, pp. 306-312, 2007. 
4. S. Çelen and K. Kahveci, "Microwave drying behaviour of tomato slices" Czech Journal of Food Sciences, vol. 31, no. 2, pp. 132-138, 2013.

5. I. Doymaz, A. S. Kipcak and S. Piskin, "Microwave drying of green bean slices: Drying kinetics and physical quality," Czech Journal of Food Sciences, vol. 33, no. 4, pp. 367-376, 2015.

6. D. Evin, "Microwave drying and moisture diffusivity of white mulberry: Experimental and mathematical modelling," Journal of Mechanical Science and Technology, vol. 25, no. 10, pp. 2711-2718, 2011.

7. T. P. K. Murthy and B. Manohar, "Microwave drying of mango ginger (Curcuma amada Roxb): Prediction of drying kinetics by mathematical modelling and artificial neural network," International Journal of Food Science and Technology, vol. 47, pp. 1229-1236, 2012.

8. S. Fang, Z. Wang, X. Hu, H. Li, W. Long and R. Wang, "Shrinkage and quality characteristics of whole fruit of Chinese jujube (Zizyphus jujuba Miller) in microwave drying," International Journal of Food Science and Technology, vol. 45, pp. 2463-2469, 2010.

9. E. Horuz and M. Maskan, "Hot air and microwave drying of pomegranate (Punica granatum L.) arils," Journal of Food Science and Technology, vol. 52, pp. 285-293, 2013.

10.F. R. Assis, R. M. S. C. Morais and A. M. M. B. Morais, "Mathematical modelling of osmotic dehydration kinetics of apple cubes," Journal of Food Processing and Preservation, vol. 41, no.3, 2017.

11.A.O.A.C. Association of the Official Analytical Chemists - Official Methods of Analysis, 2002.

12. Commission Internationale de L'Eclairage (CIE). Recommendations on uniform color spaces - Color-difference equations, psychometric color terms. CIE, Paris. Publ. 15, Suppl. 2, 1978.

13.C. H. Chong, C. L. Law, A. Figiel, A. Wojdylo and M. Oziemblowski, "Colour, phenolic content and antioxidant capacity of some fruits dehydrated by a combination of different methods," Food Chemistry, vol. 141, pp. 3889$3896,2013$.

14.V. Singleton and J. A. Rossi, Colorimetry of total phenolics with phosphormolybdic-phosphotungstic acid reagents. American Journal of Enology and Viticulture. vol. 16, pp. 144-158, 1965.

15.M. S. Gião, M. L. González-Sanjosé, M. D. Rivero-Pérez, C. I. Pereira, M. E. Pintado and F. X. Malcata, "Infusions of Portuguese medicinal plants: Dependence of final antioxidant capacity and phenol content on extraction features," Journal of the Science of Food and Agriculture, vol. 87, pp. 2638-2647, 2007.

16.G. V. Barbosa-Cánovas and H. Vega-Mercado, Dehydration of foods. New York: Chapman \& Hall; 1996.

17.G. Dadalı, D. K. Apar and B. Özbek, "Estimation of effective moisture diffusivity of okra for microwave drying," Drying Technology, vol. 25, pp. 1441-1446, 2007.

18.N. Therdthai and T. Visalrakkij, "Effect of osmotic dehydration on dielectric properties, microwave vacuum drying kinetics and quality of mangosteen," Journal of Food Science and Technology, vol. 47, pp. 2606-2612, 2012.

19.D. Zhao, C. Zhao, H. Tao, K. An, S. Ding and Z. Wang, "The effect of osmosis pretreatment on hot-air drying and microwave drying characteristics of chili (Capsicum annuum L.) flesh," International Journal of Food Science and Technology, vol. 48, pp. 1589-1595, 2013.

20.F. R. Assis, R. M. S. C. Morais and A. M. M. B. Morais, "Mathematical modelling of hot air convective drying of osmotically dehydrated apple cubes," Journal of Food Science and Technology, 2017. In press.

21.C. D. Ferreira and R. S. Pena, "Comportamento higroscópico da farinha de pupunha (Bactris gasipaes)," Food Science and Technology (Campinas), vol. 23, pp. 251-255, 2003.

22.A. K. Bejar, N. Kechaou and N. B. Mihoubi, "Effect of microwave treatment on physical and functional properties of orange (Citrus sinensis) peel and leaves," Journal of Food Processing and Technology, vol. 2, pp. 17, 2011.

23.O. P. Chauhan, A. Singh, A. Singh, P. S. Raju and A. S. Bawa, "Effects of osmotic agents on colour, textural, structural, thermal, and sensory properties of apple slices" International Journal of Food Properties, vol. 14, pp. 1037-1048, 2011.

24.N. Izli, G. Yildiz, H. Ünal, E. Işik and V. Uylaşer, "Effect of different drying methods on drying characteristics, colour, total phenolic content and antioxidant capacity of goldenberry (Physalis peruviana L.)," International Journal of Food Science and Technology, vol. 49, pp. 9-17, 2014.

25.U. Imeh and S. Khokhar, "Distribution of conjugated and free phenols in fruits: Antioxidant activity and cultivar variations," Journal of Agricultural and Food Chemistry, vol. 50, pp. 6301-6306, 2002. 
26.A. Valavanidis, T. Vlachogianni, A. Psomas, A. Zovoili and V. Siatis, "Polyphenolic profile and antioxidant activity of five apple cultivars grown under organic and conventional agricultural practices," International Journal of Food Science and Technology, vol. 44, pp. 1167-1175, 2009.

27.M. M. Novaković, S. M. Stevanović, S. Ž. Gorjanović, P. M. Jovanovic, V. V. Tešević, M. A. Janković and D. Ž. Sužnjević, "Changes of hydrogen peroxide and radical-scavenging activity of raspberry during osmotic, convective, and freeze-drying," Journal of Food Science, vol. 76, no. 4, pp. 663-668, 201. 